\title{
Antiretroviral-Drug Resistant Mutations and Genetic Diversity in HIV-1 Infected Individuals in Nigeria
}

\author{
Olubunmi Ruth Negedu-Momoh ${ }^{*}$, Olayeni Stephen Olonitola1, Lillian Emiola Odama ${ }^{2}$, \\ Edward Adekola Oladele ${ }^{3}$, Titilope Badru' ${ }^{3}$, Simon Magaji Agwale ${ }^{5}$ \\ ${ }^{1}$ Department of Microbiology, Ahmadu Bello University, Zaria, Nigeria \\ ${ }^{2}$ Department of Microbiology, Kogi State University, Ayangba, Nigeria \\ ${ }^{3}$ Family Health International (FHI 360), Abuja, Nigeria \\ ${ }^{4}$ Centre for Disease Control and Prevention, HIV Research Laboratory, Kisumu, Kenya \\ ${ }^{5}$ Innovative Biotech USA Inc, Frederick Innovative Technology Center, Frederick, USA \\ Email: bunmineges@gmail.com, onegedumomoh@ng.fhi360.org
} Helen Ineigo Inabo ${ }^{1}$, Henry Akwen Mbah ${ }^{3}$, Alex Nganga Kasembeli ${ }^{4}$, Seth Chekata Inzaule ${ }^{4}$,

Received 18 April 2014; revised 18 May 2014; accepted 30 May 2014

Copyright (C) 2014 by authors and Scientific Research Publishing Inc.

This work is licensed under the Creative Commons Attribution International License (CC BY).

http://creativecommons.org/licenses/by/4.0/

(c) (i) Open Access

\section{Abstract}

Introduction: Despite the success derived from antiretroviral therapy, drug resistance (DR) mutations are known to develop and are major impediments to treatment of HIV patients. Therefore, periodic assessment of HIVDR is needed to ensure continuous HAART efficacy. This study assessed the magnitude of drug resistance as well as HIV genetic variability in drug-naïve and treated patients in Nigeria. Methodology: Genotypic analysis was performed by sequencing plasma specimens from 40 individuals in a cross sectional study involving 202 HIV infected patients from all the six geopolitical zones of Nigeria. Sequences were analyzed for presence of HIVDR mutation using the algorithm in Stanford HIVDR database and confirmed by IAS-USA 2009 mutation list. Phylogenetic and recombination analyses were done using PAUP V4.0 and REGA V2.0 respectively. Results: Major DR mutations were detected in the reverse transcriptase (RT) gene of 5 (33\%) drug experienced and $2(8 \%)$ naïve patients. Most common mutations were M184V and K103N with no protease (PR) mutations detected. Thymidine analogue mutations (TAMs) and a complex multi resistance mutation Q151M were detected in 3 samples. Polymorphic substitutions were observed in both PR and RT gene. Phylogenetic analysis revealed Group M isolates of G (20), J (1), circulating recombinant forms: CRF02_AG (14), CRF-18-cpx (1), CRF06_cpx (3) and a unique AD recombinant (1). Conclusion: Our findings corroborate previous studies on circulating DR viruses in Nigeria while genetic diversity is on the increase. In view of ART scale-up, monitoring the resistance

${ }^{*}$ Corresponding author. 
pattern and genetic diversity will aid in appropriate prevention strategies.

Keywords

HIV, Drug Resistance, Mutation, Nigeria

\section{Introduction}

HIV-1 strains can be divided into three distinct and highly divergent groups: $\mathrm{M}$ (major), $\mathrm{O}$ (outlier), and $\mathrm{N}$ (non$\mathrm{M} / \mathrm{O}$ ). Recently, a new HIV-1 group closely related to gorilla simian immunodeficiency virus (SIVgor) was identified in a Cameroonian which showed no evidence of recombination with other HIV-1 lineages and was designated as HIV-1 group P [1]. Several genetic variants had been recognized within HIV-1 group M, including nine subtypes (A, B, C, D, F, G, H, J, and K) and many CRFs and URFs [2] with differing geographic distribution. Subtype B is the predominant subtype in the western world (Western Europe, the Americas, Japan and Australia) and is responsible for only $12 \%$ of global infections, whilst non-B subtypes predominate in the rest of the world [3]. Antiretroviral drugs were developed based on subtype-B isolates and had successfully reduced the incidence of opportunistic infections and HIV related morbidity and mortality [4]. Despite its remarkable achievement, drug resistance is the major obstacle in the management of HIV patient [5]. Drug resistant HIV causes therapeutic problems in treated and also therapy-naïve patients [6]. Emerging data has shown that viral subtype may likewise influence the effectiveness of antiretroviral treatment and that pre-existing mutations could reduce the effectiveness of ARV [7] [8]. Reduced susceptibility to ARVs has been reported in non-B subtypes than in subtype B, and that genetic differences among subtypes could result in differential patterns of resistant mutations in response to ARV pressure [9]. Meanwhile, most data on HIV-1 drug resistance mechanisms are from subtype-B viruses due to availability of genotypic and phenotypic antiretroviral drug resistance testing in the western world.

Nigeria is the most populous country in Africa with a population of 174 million in 2013 report [10] and HIV prevalence of $4.1 \%$ in 2010 antenatal survey [11] indicating 3.1 million people are living with HIV/AIDS in Nigeria. HIV 1 and 2 circulate in Nigeria [12]. In the light of expansion to increasing the number on antiretroviral therapy (ART) and creation of universal access, a total of 1,512,720 persons were estimated to require ART, of which 359,181 have been successfully placed on treatment using WHO public health approach to ART [13]. Studies on genetic diversity in Nigeria have revealed subtypes A, G, CRF02_AG, C, J, F2 and Group O among the population [14]-[16]. Apart from common subtypes, other rare complex recombinant forms like CRF06_cpx, CRF01_AE, CRF11_cpx, and A3 have also been identified [16]. Few studies have been done on HIV drug resistance and variants characterization in Nigeria because no easily applicable tool is available to carry out this study in a large population. Earlier data showed a $10 \%$ to $17 \%$ baseline resistance to major classes of ARVs of viruses in ART naïve Nigerians [16] [17]. One of the studies revealed a significant degree of primary and secondary drug resistance mutations in the RT and PR; as well as polymorphisms at positions of previously characterized drug resistance mutations in ART-naïve HIV-infected subjects from Ibadan and Saki in Oyo State [17].

Although various studies have reported existence and types of resistance mutations in Nigeria, there is still need for continuous evaluation of both the magnitude and patterns of drug resistance especially with ARV scaleup. This will aid in the development of appropriate prevention strategies to limit wide-scale treatment failure as well as plan for appropriate treatment strategies. This will also provide information regarding the current state of HIV diversity in this region. In this study, we evaluated antiretroviral drug resistant among HIV-infected ARTtreated and naïve patients and further assessed the circulating HIV-1 variants in Nigeria.

\section{Methodology}

\subsection{Study Site}

A cross sectional study was conducted on 202 HIV infected patients attending ART clinics for treatment from 2008 to 2010 from all the six geopolitical zones of Nigeria (Table 1). 
Table 1. Patient status and baseline characteristics.

\begin{tabular}{|c|c|}
\hline Patient $n=202$ & n (\%) \\
\hline \multicolumn{2}{|l|}{ Geopolitical zones/states } \\
\hline North Central: FCT & $52(26.0)$ \\
\hline North East: Taraba, Adamawa & $21(10.0)$ \\
\hline North West: Kano & $37(18.0)$ \\
\hline South East: Anambra & $54(27.0)$ \\
\hline South South: Cross River & $14(7.0)$ \\
\hline South West: Lagos & $12(6.0)$ \\
\hline${ }^{*}$ Missing & $12(6.0)$ \\
\hline \multicolumn{2}{|l|}{ Age } \\
\hline Male & $72(35.6)$ \\
\hline Female & $130(64.4)$ \\
\hline \multicolumn{2}{|l|}{ ART drug status } \\
\hline ART Experienced & $160(79.2)$ \\
\hline Naïve (Non-ART) & $42(20.8)$ \\
\hline \multicolumn{2}{|l|}{ 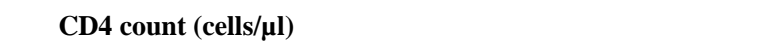 } \\
\hline$\leq 350$ & $101(50.0)$ \\
\hline$>350$ & $101(50.0)$ \\
\hline Mean & 422 \\
\hline Median (IQR) & $348(217-535)$ \\
\hline \multicolumn{2}{|l|}{ Viral Load (copies/ml) } \\
\hline$<50$ & $92(45.5)$ \\
\hline$\geq 50$ & $110(54.5)$ \\
\hline Mean & 12,840 \\
\hline Median (IQR) & $66(50-766)$ \\
\hline \multicolumn{2}{|l|}{ ARV Regimen $(n=160)$} \\
\hline 1st line & $153(94.6)$ \\
\hline 2nd line & $7(5.4)$ \\
\hline
\end{tabular}

ART: Antiretroviral therapy; non-ART: No Antiretroviral therapy. (No treatment or drugnaïve); IQR: Interquartile range; " missing—Data on the patient origin were not available on the questionnaire.

\subsection{Study Population and Sample Collection}

Study population included both ART naive and experienced patients ( $\geq 3$ months). Patients who were sick at the time of sample collection and those with incomplete questionnaire were excluded from the study.

Baseline characteristic collected includes age, sex, place of birth, state of origin, ethnicity and mode of infection if known, ARV drug, date of commencement. Blood was drawn for baseline immunological and virological testing at sites. Selection for genotyping assay was based on samples that met the criteria of a viral load $\geq 1000$ copies per ml.

\subsection{Viral Load and Viral RNA Isolation}

Viral load (plasma HIV-1 RNA) was quantified using b-DNA method, Versant HIV I-RNA 3.0 (Bayer Diagnostics, Emeryville, CA, USA). Viral RNA particles was extracted from 48 viral load plasma samples that met the criteria of detectable viral load copies greater or equal to 1000 copies per ml using QIA amp viral RNA mini kit, following the manufacturer’s protocol (Qaigen Inc. Chatworth, CA).

\subsection{HIV-1 Genotyping}

HIV-1 genotyping for the pol-gene region was done using the CDC in-house genotyping system to generate 1050 base pair fragment consisting of 1 - 99 amino acids of the protease region and codons 1 - 251 of the RT re- 
gion. Detailed procedure for this assay has previously been described [18] [19]. Briefly, $15 \mu$ of nucleic acid extracts from plasma were subjected to a one-step RT-PCR using RT forward and reverse primers and SuperScript ${ }^{\mathrm{TM}}$ III one step RT-PCR systems with Platinum ${ }^{\circledR}$ Taq high fidelity following the manufacturer's protocol (Invitrogen, Carlsbad, CA). For nested PCR, $4 \mu \mathrm{l}$ of the RT-PCR product was used in the $2^{\text {nd }}$ round nested PCR using inner primers to yield 1062 base pair amplicon. Sequencing was then done using six overlapping primers and analyzed using the ABI 3100 genetic analyzer. Confirmation of base-calling and sequence editing was done using the Sequencher V 4.6 (Gene codes) software while drug resistance interpretation was performed using the Stanford genotyping drug resistance interpretation algorithm (V 4.2.6) (http://hivdb.stanford.edu/) whilst using the International AIDS Society 2009 mutation list for confirmation [20].

\subsection{Phylogenetic Analyses}

Sequence alignment was done using sequence alignment editor (Se-Al V 2.0) to generate base pairs sequences devoid of gaps [21]. Phylogenetic analysis was then performed with Phylogenetic Analysis Using Parsimony (PAUP) Version 4.0 to generate neighbor-joining phylogenetic trees [22]. National Center for Biotechnology Information (NCBI) and Rega HIV subtyping tool version 2.0 was used to further evaluate accurately the classification of recombinant and non-recombinant genotypes using boot scanning methods. The reliability of the tree was tested with 1000 bootstrap analyses.

\subsection{Nucleotide Sequence Accession Numbers}

Sequences generated from this study have been deposited in the GenBank database with accession numbers HQ 845921 to HQ 845960. The GenBank numbers are used in this report.

\subsection{Statistical Analysis}

Statistical analyses were performed using STATA version 10.0 (Stata Corporation, College Station, TX). Differences between groups were compared using Pearson's Chi-squared test. All statistical tests were two-sided and $P$ value $<0.05$ was considered statistically significant.

\section{Results}

\subsection{Patient Characteristics}

Of the 202 HIV infected patients, female patients were 130 (64\%). The median age of the patients was 33 yrs old (interquartile range (IQR): 28 - 40). The median (IQR) CD4 cell count and plasma viral load level were 348 (217 - 535) cells/ $\mu \mathrm{l}$ and 66 (50 - 766) copies/ml respectively (Table 1). ART patients sample analyzed were 160 (79.2\%) were while 42 (20.8\%) were drug-naïve. Among the ART patients, 153 (94.6\%) were on first line regimen of highly active antiretroviral therapy (HAART) based on the drugs available in the National guideline (combination of $3 \mathrm{ARVs}$ of two nucleoside/nucleotide reverse transcriptase inhibitors and one non-nucleoside reverse transcriptase inhibitor). Those on second line were 7 (5.4\%). Median month on treatment was 14 months (IQR: 8 - 25) (Table 1).

\subsection{Evaluation of Drug Resistance Mutations}

Of the 48 samples that met genotyping criteria, 40 were successfully sequenced (15 ART and 25 drug-naïve). Drug resistance mutation was identified in 5 ART patients (5/15, 33\%) and 2 drug-naïve $(2 / 25,8 \%)$ at the RT region of the pol gene (Table 2). No mutation conferring resistance to Protease inhibitors (PIs) were seen in this population. Of the resistance mutations observed $6(6 / 7)$ confers resistance to nucleotide reverse transcriptase inhibitors (NRTIs) and 6 (6/7) non-nucleotide reverse transcriptase inhibitors NNRTIs respectively of the RT region. Most commonly occurring mutation was M184V (5/40, 13\%) and K103N (5/40, 13\%) which confers resistance to NRTIs and NNRTIs respectively. Complex multi-drug resistance mutations Q151M occurred with other secondary mutations V75M and F77L in one of the ART patient; while thymidine analogue mutations (TAMs): M41L, L210W and T215Y occurred in two of the ART patient. Other NNRTI mutations observed were Y181C (2), G190G (1) (Table 2 \& Table 3).

Among the ARV naive patients, singleton M41L and K103N resistant mutations conferring resistance to 
Table 2. Summary of resistance profile in ART experienced and naïve patients.

\begin{tabular}{|c|c|c|c|c|c|}
\hline Sample ID & GenBank ID & $\begin{array}{l}\text { ARV Drug } \\
\text { combination }\end{array}$ & Subtypes & $\begin{array}{l}\text { NRTI resistance } \\
\text { mutations }\end{array}$ & $\begin{array}{l}\text { NNRTI resistance } \\
\text { mutations }\end{array}$ \\
\hline NG.SCBH.8960 & HQ845929 & AZT, 3TC, NVP & CRF-02-AG & $\begin{array}{l}\text { M41L, L74IL, M184V, } \\
\text { L210W, T215Y, }\end{array}$ & K103N, \\
\hline NG.DOC.10208 & HQ845935 & ABC/3TC/LPV/RTV & G & $\begin{array}{c}V 75 M, F 77 L, Q 151 M, \\
M 184 V\end{array}$ & Y181C, G190AG, \\
\hline NG.DOC.10266 & HQ845937 & d4T, 3TC, NVP & G & M184V, & K103N, M230L, \\
\hline NG.DOC.10267 & HQ845938 & TDF, FTC, NVP & CRF-02-AG & M184V, & K103N, Y181C, \\
\hline NG.DOC.13816 & HQ845960 & AZT, 3TC, NVP & CRF-02-AG & $\begin{array}{l}M 41 L, \text { L74IL, M184V, } \\
\text { L210W, T215Y, }\end{array}$ & K103N, \\
\hline NG.DOC.13742 & HQ845953 & Drug naïve & CRF-06-cpx & $M 41 L$ & \\
\hline NG.DOC.13805 & HQ845958 & Drug naïve & $\mathrm{J}$ & & $K 103 N$ \\
\hline
\end{tabular}

AZT; Zidovudine, 3TC; Lamivudine, NVP; Nevirapine, TDF; Tenofovir; FCT; Emtricitabine, LPV/TRV; Lopinavir-Ritonavir, d4T; Stavudine, ABC; Abacavir. Italic indicates key mutations.

Table 3. Resistance mutations selected by drug.

\begin{tabular}{|c|c|c|c|c|}
\hline ART class & Mutations & $\begin{array}{c}\text { ART experienced } \\
n(\%)=15\end{array}$ & $\begin{array}{l}\text { Drug naïve } \\
\text { n }(\%)=25\end{array}$ & $\begin{array}{c}\text { Total } \\
\text { n }(\%)=40\end{array}$ \\
\hline \multirow[t]{8}{*}{ NRTI } & M41L & $2(13)$ & $1(4)$ & $3(8)$ \\
\hline & L74I & $2(13)$ & - & $2(5)$ \\
\hline & V75M & $1(7)$ & - & $1(3)$ \\
\hline & F77L & $1(7)$ & - & $1(3)$ \\
\hline & Q151M & $1(7)$ & - & $1(3)$ \\
\hline & M184V & $5(33)$ & - & $5(13)$ \\
\hline & L210W & $2(13)$ & - & $2(5)$ \\
\hline & $\mathrm{T} 215 \mathrm{Y}$ & $2(13)$ & - & $2(5)$ \\
\hline \multirow[t]{2}{*}{ NNRTI } & K103N & $4(27)$ & $1(4)$ & $5(13)$ \\
\hline & Y181C & 2 (13) & - & $2(5)$ \\
\hline
\end{tabular}

RT; Reverse Transcriptase, NRTI; Nucleotide Reverse Transcriptase Inhibitors, Non-Nucleotide Reverse Transcriptase Inhibitors.

NRTI and NNRTI respectively were identified.

Polymorphic substitutions were observed in both the PR: I13V, K20I, M36I, R41K, H69K, V82I and L89M and the RT: R211K, A98G/S/AS regions of the pol gene. Subtype specific polymorphisms A98AS/S/G (4/20; 20\%;) and V82I (18/20; 90\%) were observed among subtype G strains.

\subsection{Genetic Variability}

Phylogenetic analysis revealed Group $\mathrm{M}$ isolates by different clusters (Figure 1). The predominant subtype was subtype G (50\%, 20/40), followed by circulating recombinant forms CRF02_AG (35\%, 14/40,) CRF06_cpx (7.5\%, 3/40), CRF-18-cpx $(2.5 \%, 1 / 40)$, subtype $\mathrm{J}(2.5 \%, 1 / 40)$, and a unique recombinant $\mathrm{AD}(2.5 \%, 1 / 40)$. Subtype J and CRF06_cpx were the two strains found in the drug-naïve individuals.

\section{Discussion}

This study revealed key resistance mutations in HIV infected patients and also established that diverse recombinant forms of HIV are on the increase in Nigeria.

Analysis of patients ARVs regimen status revealed that majority of the patients (94.6\%) were on first line regimen of highly active antiretroviral therapy (HAART) while the rest were on second line treatment based on the drug available as in the National guideline. The nucleoside backbone used for treatment in this setting are, AZT/ 3TC, TDF/FTC, d4T/3TC and ABC/3TC. Lopinavir/ritonavir serves as the protease inhibitors for the 


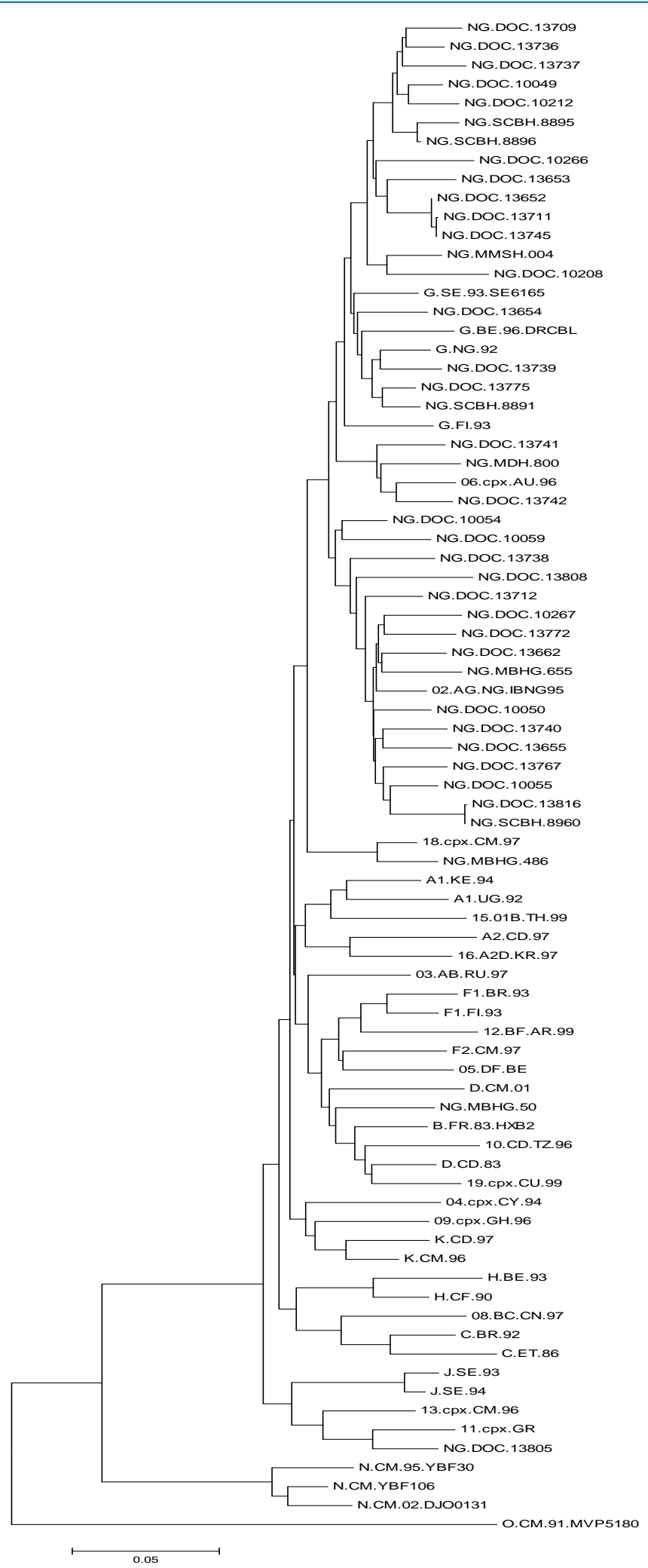

Neighbor Joining tree of 40 Nigerian samples sequenced are reported and preceded by the prefix "NG," underline, indicating the country (NG—Nigeria) of specimen collection and other code that follows represented the code for site where samples were collected and the hospital assigned number (e.g., NG.DOC.13741). The scale bar indicates an evolutionary distance of 10 nucleotides per position in the sequence.

Figure 1. Phylogenetic analysis of Nigerian HIV-1 sequences of the pol region. 
nucleoside backbone combination of the second line. Virtually all the regimen except Tenofovir based has Lamivudine (3TC) in their combinations.

Analysis of the sequence revealed mutations conferring resistance at the RT region of the pol gene. This agrees with extensive use of NRTI in the first line regimen for the treatment of infected individuals in Nigeria. Mutations conferring resistance observed were M41L, Q151M, M184V, L210W, T215Y, K103N, and Y181C. Absence of resistance mutation at the PR region may be due to limited use of PI in Nigeria and only found among the second line regimens. M184V resistance mutation was commonly observed in the RT region among the ART experienced patients. This mutation is selected by use of lamivudine (3TC), Emtricitabine (FTC), Abacavir (ABC) but confers high level resistance to lamivudine and is usually the first to develop in isolates from patients receiving incompletely suppressive lamivudine-containing regimens [23]. Thymidine analogue mutations (TAMs) M41L, L210W and T215Y were observed in two of the patients on first line regimen of CRF_02AG strains. Presence of TAMs calls for public health concern as it promotes resistance to almost all NRTI analogues and is most often selected by zidovudine and stavudine-containing regimens. The two patients NG.SCBH.8960 and NG.DOC.13816 already failing therapy as the current mutation is selected by zidovudine based regimen.

Q151M a complex resistance mutation was detected in a subtype G treated patient (NG.DOC.10208) on second line regimen and occurred together with secondary mutation at positions 75 and 77 . Q151M confer high level resistance to most NRTIs except Lamivudine and Tenofovir [24] [25] thus its presence in the study is also a major public health concern. Presence of Q151M mutation has not been highlighted by past studies in Nigeria.

Mutation conferring resistance to NNRTIs were seen in 6 of the samples occurring as K103N (12.5\%) and Y181C (5\%) as well as G190AG (2.5\%) and M230L (2.5\%). K103N was the second common mutation after M184V and is known to be the predominant mutation in patients receiving NNRTIs [26] and may cause cross resistance to all other NNRTI drug [27].

Y181C is known to cause resistance to NNRTIs mostly nevirapine and delavirdine [28]. G190AG found in sample NG.DOC.10208 is an uncommon mutation, but G190A which is a close mutation is known to have high level resistance to nevirapine and an intermediate levels of resistance to efavirenz [28] [29].

Drug resistance mutations were detected in the RT gene of $2(2 / 25 ; 8 \%)$ drug-naïve persons. Circulation of HIV isolates containing resistance mutations in drug-naïve individuals was previously described in Nigeria [30] [31] and is quite worrisome as transmitted drug resistance will affect the choice of the most effective treatment regime. Early data suggested a $10 \%$ to $17 \%$ baseline resistance to major classes of ARVs in viruses from Nigerians not undergoing ART [16] [17]. Other studies have observed that about $10 \%$ of newly infected patients' harbors virus that is at least partially resistant to one or more antiretroviral drugs [32]. One of the drug-naïve patient (NG.DOC.13742) having CRF-06-cpx displayed a singleton M41L mutation at the NRTI and the second one (NG.DOC.13805) having subtype J revealed K103N mutation at NNRTI region. M41L is known to be associated with development of resistance to AZT [33], while V60I, an unusual mutation was found at the RT region. Some studies have mentioned that viruses with a single resistance associated amino acid substitution (singleton mutation) may constitute a particular interpretation problem as some of them may appear both as natural sequence polymorphism and as drug resistance mutation, and that M41L may represent a rare "natural" sequence variant when it occurs on its own [34]. It is estimated that every possible single point mutation occurs between 104 and 105 times per day in an untreated HIV-1-infected individual and that double mutants also occur commonly [35]. Therefore, most drug-resistance mutations are probably present prior to the start of therapy. The mutational patterns noticed in the drug-naïve individuals were not complex. This was also reported similarly in other studies both from Nigeria [30] and other African countries [36] [37].Transmission of drug resistance from treatment-experienced patients to newly infected persons has been observed repeatedly in countries with long term use of antiretroviral drug [38] thus, raising major public health concerns [39]. Therefore clinical management of patients who have never been exposed to therapy may be unfavourably affected [40]. The occurrence of this intrinsic drug-resistant virus in HIV drug-naïve patients could imply that many drug experienced patients continue to engage in risk related behaviour. The public health implications of this include the need to intensify programs directed at such patients to address prevention of transmission.

Other mutations/polymorphic substitutions observed in both the PR (I13V, K20I, M36I, R41K, H69K, V82I and $\mathrm{L} 89 \mathrm{M})$ and the RT (R211K) regions of the pol gene. Mutations at these positions do not cause high level drug resistance, but they contribute to drug resistance when present together with certain primary protease mutations [41]. The higher frequency of protease polymorphism in non-B isolates, including protease positions 20,36 , 
63, 82 and 93, has raised concern that PI treatment of non-subtype B infected persons could be less effective than that of subtype B [7]. A similar mutations/polymorphic substitutions in the protease region of some Nigerian isolates had been reported [30].

The Phylogenetic analysis agrees with results of previous studies in Nigeria that the predominant variants of HIV-1 are subtype G and the circulating recombinant form CRF02_AG [17] [42]. However subtype A which had been reported as the second most prevalent in the country was not found in the study, this may be due to the limited sample size used for the study. Subtype J, a known rare subtype was observed in one of the drug-naïve. Meanwhile, the continuous presence of CRF02_AG as compared to previous study is suggesting the dominance of these recombinants in the country and in West Africa [43] and the epidemiologic importance in future research. Increasing number of recombinants was noticed in the study, the CRF06_cpx and a new form CRF18_ cpx. CRF06_cpx were found in two drug-naïve individuals. This is a complex mosaic virus that had been found in continents like Europe and Australia and likewise in some West Africa Countries such as Ivory Coast, Niger, Mali and Senegal [42] [44].

CRF18_cpx, a novel HIV-1 circulating recombinant form was found in the North Eastern region of Nigeria, basically on the border boundary to Cameroun. This virus had been known to originate from Central Africa and had been found in Cameroun [45]. Cameroun share boundary with Nigeria with high diversity of circulating HIV-1 genetic forms and this closeness may likely influence the growing increase in HIV diversity in Nigeria. The identification of novel CRF may have practical implications in the management of patients and also in development of vaccine.

A unique recombinant form (URFs) of subtype A and D was observed in one of the sample; URF of subtype $\mathrm{AD}$ is known to circulate in East Africa [46] and Ghana [47]. Its presence may reflect an incidence of coinfections or superinfections with diverse viral strains thus increasing the genetic complexity of the HIV-1 epidemic in West Africa.

A major limitations of this study is that it was cross sectional, thus patients were not followed up to assess the outcome of their response to treatment and if the resistance mutations seen in the drug-naïve will be observed later in the course of treatment. The criteria for genotyping selection of a viral load $\geq 1000$ copies per ml may have missed some mutation and variant in circulation.

The findings provide current information with regard to drug resistance profile among treatment experienced and naive population as well as the genetic diversity which is helpful in guiding the use of the different ARV drugs in use in Nigeria.

\section{Conclusion}

In summary, our results indicate that HIV-1 genetic diversity in Nigeria is increasing and presence of drug resistance mutations agrees with components of the first-line drug taken by majority. Thus, continuous assessment is needed to monitor the evolving diverse strains and potential impact of drug resistance on ART programs in Nigeria in order to ensure continuance efficacy of the limited available ART.

\section{Acknowledgements}

The authors would like to acknowledge the technical support provided by Dr. Clement Zeh and his HIV Research laboratory team at Centre for Disease Control and Prevention, HIV Research Laboratory, Kisumu, Kenya for the considerable help and support in this work. I also wish to thank the laboratory staff of the following facilities who assisted in the collection and initial processing of the samples: St. Charles Borromeo, Onitsha, Nigeria; Muritala Mohammed Specialist Hospital, Kano; Mambilla Baptist Hospital, Gembu, Taraba; Daughters of Charity, Kubwa, Abuja (DOC); Federal Medical Center, Yola; Holy Family Catholic Hospital, Ikom; Mainland Hospital, Yaba and Maitama District Hospital, Abuja. The views expressed herein is that of the authors and do not necessarily reflect those of any institution.

\section{Authors' Contributions}

Conceived and designed of experiment: ORN-M, SOO, LEO, HII, SMA; Performed the experiment: ORN-M, ANK, SCI, analyzed the data: ORN-M, ANK, SCI, TB, HAM, SMA; wrote the paper: ORN-M; reviewed the manuscript: ORN- M, S.C. Inzaule, EAO, HAM, SMA. 


\section{Ethical Approval}

Ethical approval for the main study was obtained from ethical review committee for Ahmadu Bello University. Written informed consent was obtained from each participant prior to the study initiation.

\section{Competing Interest}

The authors declare that there is no financial or personal relationship(s) that may have inappropriately influenced the writing of this article.

\section{References}

[1] Takehisa, J. and Miura, T. (2010) The Origin and Evolution of HIV. Journal of Japanese Clinical Medicine, 68, 410-414

[2] Robertson, D.L., Anderson, J.P., Bradac, J.A., et al. (2000) HIV-1 Nomenclature Proposal. Science, 288, 55-56. http://dx.doi.org/10.1126/science.288.5463.55d

[3] Osmanov, S., Pattou, C., Walker, N., Schwardländer, B. and Esparza, J. (2002) Estimated Global Distribution and Regional Spread of HIV-1 Genetic Subtypes in the Year 2000. Journal of Acquired Immune Deficiency Syndromes, 29, 184-190. http://dx.doi.org/10.1097/00042560-200202010-00013

[4] Egger, M., Hirschel, B., Francioli, P., Sudre, P., Wirz, M., Flepp, M., Rickenbach, M., Malinverni, R., Vernazza, P. and Battegay, M. (1997) Impact of New Antiretroviral Combination Therapies in HIV Infected Patients in Switzerland: Prospective Multicentre Study.. BMJ, 315, 1194. http://dx.doi.org/10.1136/bmj.315.7117.1194

[5] Shafer, R.W. (2002) Genotypic Testing for Human Immunodeficiency Virus Type 1 Drug Resistance. Clinical Microbiology Reviews, 15, 247-277. http://dx.doi.org/10.1128/CMR.15.2.247-277.2002

[6] Yerly, S., Kaiser, L., Race, E., Bru, J.P., Clavel, F. and Perrin, L. (1999) Transmission of Antiretroviral-Drug-Resistant HIV-1 Variants. Lancet, 354, 729-733. http://dx.doi.org/10.1016/S0140-6736(98)12262-6

[7] Wainberg, M.A. (2004) HIV-1 Subtype Distribution and the Problem of Drug Resistance. AIDS, 18, S63-S68. http://dx.doi.org/10.1097/00002030-200406003-00012

[8] Kantor, R. and Katzenstein, D. (2004) Drug Resistance in Non-Subtype B HIV-1. Journal of Clinical Virology, 29, 152-159. http://dx.doi.org/10.1016/S1386-6532(03)00115-X

[9] Wainberg, M.A. and Brenner, B.G. (2010) Role of HIV Subtype Diversity in the Development of Resistance to Antiviral Drugs. Viruses, 2, 2493-2508. http://dx.doi.org/10.3390/v2112493

[10] Population Reference Bureau (2013) World Population Data Sheet. www.prb.org

[11] Federal Ministry of Health, Nigeria (2010) Technical Report on HIV Sentinel Survey among Pregnant Women Attending Antenatal Clinics in Nigeria.

[12] Olaleye, O.D., Bernstein, L., Ekweozor, C.C., Sheng, Z., Omilabu, S.A., Li, X.Y., Sullivan-Halley, J and Rasheed, S. (1993) Prevalence of Human Immunodeficiency Virus Types 1 and 2 Infections in Nigeria. The Journal of Infectious Diseases, 167, 710-714. http://dx.doi.org/10.1093/infdis/167.3.710

[13] Federal Ministry of Health, Nigeria (2010) National Guidelines for HIV/AIDS Treatment and Care in Adolescence and adults, 60-62.

[14] Howard, T.M. and Rasheed, S. (1996) Genomic Structure and Nucleotide Sequence Analysis of a New HIV Type 1 Subtype A Strain from Nigeria. AIDS Research and Human Retroviruses, 12, 1413-1425. http://dx.doi.org/10.1089/aid.1996.12.1413

[15] Agwale, S.M., Robbins, K.E., Odama, L., et al. (2001) Development of an env gp41-Based Heteroduplex Mobility Assay for Rapid Human Immunodeficiency Virus Type 1 Subtyping. Journal of Clinical Microbiology, 39, $2110-2114$. http://dx.doi.org/10.1128/JCM.39.6.2110-2114.2001

[16] Agwale, S.M., Zeh, C., Robbins, K.E., Odama, L., Saekhou, A., Edubio, A., Njoku, M., Sani-Gwarzo, N., Gboun, M.S., Gao, F., Reitz, M., Hone, D., Pieniazek, D., Wambebe, C. and Kalish, M.L. (2002) Molecular Surveillance of HIV-1 Field Strains in Nigeria in Preparation for Vaccine Trials. Vaccine, 20, 2131-2139. http://dx.doi.org/10.1016/S0264-410X(02)00059-2

[17] Ojesina, A.I., Sankalé, J.L., Odaibo, G., Langevin, S., Meloni, S.T., Sarr, A.D., Olaleye, D. and Kanki, P.J. (2006) Subtype-Specific Patterns in HIV Type 1 Reverse Transcriptase and Protease in Oyo State, Nigeria: Implications for Drug Resistance and Host Response. AIDS Research and Human Retroviruses, 22, 770-779. http://dx.doi.org/10.1089/aid.2006.22.770

[18] McNulty, A., Jennings, C., Bennett, D., Fitzgibbon, J., Bremer, J.W., Ussery, M., Kalish, M.L., Heneine, W. and 
García-Lerma, J.G. (2007) Evaluation of Dried Blood Spots for Human Immunodeficiency Virus Type 1 Drug Resistance Testing. Journal of Clinical Microbiology, 45, 517-521. http://dx.doi.org/10.1128/JCM.02016-06

[19] Yang, C., McNulty, A., Diallo, K., Zhang, J., Titanji, B., Kassim, S., Wadonda-Kabondo, N., Aberle-Grasse, J., Kibuka, T., Ndumbe, P.M., Vedapuri, S., Zhou, Z.Y., Chilima, B. and Nkengasong, J.N. (2010) Development and Application of a Broadly Sensitive Dried-Blood-Spot-Based Genotyping Assay for Global Surveillance of HIV-1 Drug Resistance. Journal of Clinical Microbiology, 48, 3158-3164. http://dx.doi.org/10.1128/JCM.00564-10

[20] Johnson, V.A., Brun-Vézinet, F., Clotet, B., Günthard, H.F., Kuritzkes, D.R., Pillay, D., Schapiro, J.M. and Richman, D.D. (2010) Update of the Drug Resistance Mutations in HIV-1: December 2010. Topics in HIV Medicine, 18, 156163.

[21] Rambaut, A. (2002) Sequence Alignment Editor (Version 2.0). Oxford University. http://tree.bio.ed.ac.uk/software/seal/

[22] Swofford, D.L., Begle, D.P. and Dc, W. (2000) Phylogenetic Analysis Using Parsimony, Version 4.0b4. Sinauer, Sunderland.

[23] Mouroux, M., Descamps, D., Izopet, J., Yvon, A., Delaugerre, C., Matheron, S., Coutellier, A., Valantin, M.A., Bonmarchand, M., Agut, H., Massip, P., Costagliola, D., Katlama, C., Brun-Vezinet, F. and Calvez, V. (2001) Low-Rate Emergence of Thymidine Analogue Mutations and Multi-Drug Resistance Mutations in the HIV-1 Reverse Transcriptase Gene in Therapy-Naive Patients Receiving Stavudine Plus Lamivudine Combination Therapy. Antiviral Therapy, 6, 179-183.

[24] Iversen, A.K.N., Shafer, R.W., Wehrly, K., Winters, M.A., Mullins, J.I., Chesebro, B. and Merigan, T.C. (1996) Multidrug-Resistant Human Immunodeficiency Virus Type 1 Strains Resulting from Combination Antiretroviral Therapy. Journal of Virology, 70, 1086-1090.

[25] Miller, V. and Larder, B.A. (2001) Mutational Patterns in the HIV Genome and Cross-Resistance Following Nucleoside and Nucleotide Analogue Drug Exposure. Antiviral Therapy, 6, 25-44.

[26] Deeks, S.G. (2001) Nonnucleoside Reverse Transcriptase Inhibitor Resistance. JAIDS Journal of Acquired Immune Deficiency Syndromes, 26, S25-S33.

[27] D’Aquila, R.T., Schapiro, J.M., Brun-Vezinet, F., et al. (2002) Drug Resistance Mutations in HIV-1. Topics in HIV Medicine, 10, 21-25. (Special Contribution)

[28] Petropoulos, C.J., Parkin, N.T., Limoli, K.L., Lie, Y.S., Wrin, T., Huang, W., Tian, H., Smith, D., Winslow, G.A., Capon, D.J. and Whitcomb, J.M. (2000) A Novel Phenotypic Drug Susceptibility Assay for Human Immunodeficiency Virus Type 1. Antimicrobial Agents and Chemotherapy, 44, 920-928. http://dx.doi.org/10.1128/AAC.44.4.920-928.2000

[29] Huang, W., Gamarnik, A., Limoli, K., Petropoulos, C.J. and Whitcomb, J.M. (2003) Amino Acid Substitutions at Position 190 of Human Immunodeficiency Virus Type 1 Reverse Transcriptase Increase Susceptibility to Delavirdine and Impair Virus Replication. Journal of Virology, 77, 1512-1523. http://dx.doi.org/10.1128/JVI.77.2.1512-1523.2003

[30] Agwale, S.M., Zeh, C., Paxinos, E., Odama, L., Pienazek, D., Wambebe, C., Kalish, M.L. and Ziermann, R. (2006) Genotypic and Phenotypic Analyses of Human Immunodeficiency Virus Type 1 in Antiretroviral Drug-Naive Nigerian Patients. AIDS Research and Human Retroviruses, 22, 22-26. http://dx.doi.org/10.1089/aid.2006.22.22

[31] Paxinos, E., Womac, C., Galovich, J., et al. (2004) Emergence of Drug Resistant Human Immunodeficiency Virus during the Era of Massive Antiretroviral therapy in Nigeria. Aids Vaccines and Related Topics, Research Signpost, Trivandrum, 121-123.

[32] Cane, P., Chrystie, I., Dunn, D., et al. (2005) Time Trends in Primary Resistance to HIV Drugs in the United Kingdom: Multicentre Observational Study. British Medical Journal, 331, 1368. http://dx.doi.org/10.1136/bmj.38665.534595.55

[33] Boucher, C.A., O’Sullivan, E., Mulder, J.W., Ramautarsing, C., Kellam, P., Darby, G., Lange, J.M., Goudsmit, J. and Larder, B.A. (1992) Ordered Appearance of Zidovudine Resistance Mutations during Treatment of 18 Human Immunodeficiency Virus-Positive Subjects. Journal of Infectious Diseases, 165, 105-110. http://dx.doi.org/10.1093/infdis/165.1.105

[34] Lindström, A., Ohlis, A., Huigen, M., Nijhuis, M., Berglund, T., Bratt, G., Sandström, E. and Albert, J. (2006) HIV-1 Transmission Cluster with M41L "Singleton” Mutation and Decreased Transmission of Resistance in Newly Diagnosed Swedish Homosexual Men. Antiviral Therapy, 11, 1031-1039.

[35] Coffin, J.M. (1995) HIV Population Dynamics in Vivo: Implications for Genetic Variation, Pathogenesis, and Therapy. Science, 267, 483-489. http://dx.doi.org/10.1126/science.7824947

[36] Adjé-Touré, C., Bilé, C.E., Borget, M.Y., Hertog, K., Maurice, C., Nolan, M.L. and Nkengasong, J.N. (2003) Polymorphism in Protease and Reverse Transcriptase and Phenotypic Drug Resistance of HIV-1 Recombinant CRF02_AG Isolates from Patients with No Prior Use of Antiretroviral Drugs in Abidjan, Côte d'Ivoire. JAIDS Journal of Acquired Immune Deficiency Syndromes, 1, 111-113. http://dx.doi.org/10.1097/00126334-200309010-00016 
[37] Vergne, L., Diagbouga, S., Kouanfack, C., Aghokeng, A., Butel, C., Laurent, C., Noumssi, N., Tardy, M., Sawadogo, A., Drabo, J., Hien, H., Zekeng, L., Delaporte, E. and Peeters, M. (2006) HIV-1 Drug-Resistance Mutations among Newly Diagnosed Patients before Scaling-Up Programmes in Burkina Faso and Cameroon. Antiviral Therapy, 11, 575-579.

[38] Tanuri, A., Caridea, E., Dantas, M.C., et al. (2002) Prevalence of Mutations Related to HIV-1 Antiretroviral Resistance in Brazilian Patients Failing HAART. Journal of Clinical Virology, 25, 39-46. http://dx.doi.org/10.1016/S1386-6532(01)00249-9

[39] Wainberg, M.A. and Friedland, G. (1998) Public Health Implications of Antiretroviral Therapy and HIV Drug Resistance. JAMA, 279, 1977-1983. http://dx.doi.org/10.1001/jama.279.24.1977

[40] Hirsch, M.S., Brun-Vézinet, F., Clotet, B., Conway, B., Kuritzkes, D.R., D’Aquila, R.T., Demeter, L.M., Hammer, S.M., Johnson, V.A., Loveday, C., Mellors, J.W., Jacobsen, D.M. and Richman, D.D. (2003) Antiretroviral Drug Resistance Testing in Adults Infected with Human Immunodeficiency Virus Type 1: 2003 Recommendations of an International AIDS Society-USA Panel. Clinical Infectious Diseases, 37, 113-128. http://dx.doi.org/10.1086/375597

[41] Soriano, V. and de Mendoza, C. (2002) Genetic Mechanisms of Resistance to Protease Inhibitors and Entry Inhibitors. HIV Clinical Trials, 3, 249-257. http://dx.doi.org/10.1310/3C93-6MTH-9MAR-U0BE

[42] Peeters, M. and Sharp, P.M. (2000) Genetic Diversity of HIV-1 : The Moving Target. AIDS, 14, S129-S140.

[43] McCutchan, F.E., Carr, J.K., Bajani, M., Sanders-Buell, E., Harry, T.O., Stoeckli, T.C., Robbins, K.E., Gashau, W., Nasidi, A., Janssens, W. and Kalish, M.L. (1999) Subtype G and Multiple forms of A/G Intersubtype Recombinant Human Immunodeficiency Virus Type 1 in Nigeria. Virology, 254, 226-234. http://dx.doi.org/10.1006/viro.1998.9505

[44] Montavon, C., Bibollet-Ruche, F., Robertson, D., Koumare, B., Mulanga, C., Esu-Williams, E., Toure, C., Mboup, S., Saman, E., Delaporte, E. and Peeters, M. (1999) The Identification of a Complex A/G/I/J Recombinant HIV Type 1 Virus in Various West African Countries. AIDS Research and Human Retroviruses, 15, 1707-1712. http://dx.doi.org/10.1089/088922299309757

[45] Vergne, L., Bourgeois, A., Mpoudi-Ngole, E., Mougnutou, R., Mbuagbaw, J., Liegeois, F., Laurent, C., Butel, C., Zekeng, L., Delaporte, E. and Peeters, M. (2003) Biological and Genetic Characteristics of HIV Infections in Cameroon Reveals dual Group M and O Infections and a Correlation between SI-Inducing Phenotype of the Predominant CRF02_AG Variant and Disease Stage. Virology, 310, 254-266. http://dx.doi.org/10.1016/S0042-6822(03)00167-3

[46] Lihana, R.W., Ssemwanga, D., Abimiku, A. and Ndembi, N. (2012) Update on HIV-1 Diversity in Africa: A Decade in Review. AIDS Reviews, 14, 83-100.

[47] Delgado, E., Ampofo, W.K., Sierra, M., Torpey, K., Pérez-Álvarez, L., Bonney, E.Y., Mukadi, Y.D., Lartey, M., Nyarko, C., Amenyah, R.N., Thomson, M.M. and Nájera, R. (2008) High Prevalence of Unique Recombinant Forms of HIV-1 in Ghana: Molecular Epidemiology from an Antiretroviral Resistance Study. JAIDS Journal of Acquired Immune Deficiency Syndromes, 48, 599-606. http://dx.doi.org/10.1097/QAI.0b013e3181806c0e 
Scientific Research Publishing (SCIRP) is one of the largest Open Access journal publishers. It is currently publishing more than 200 open access, online, peer-reviewed journals covering a wide range of academic disciplines. SCIRP serves the worldwide academic communities and contributes to the progress and application of science with its publication.

Other selected journals from SCIRP are listed as below. Submit your manuscript to us via either submit@scirp.org or Online Submission Portal.
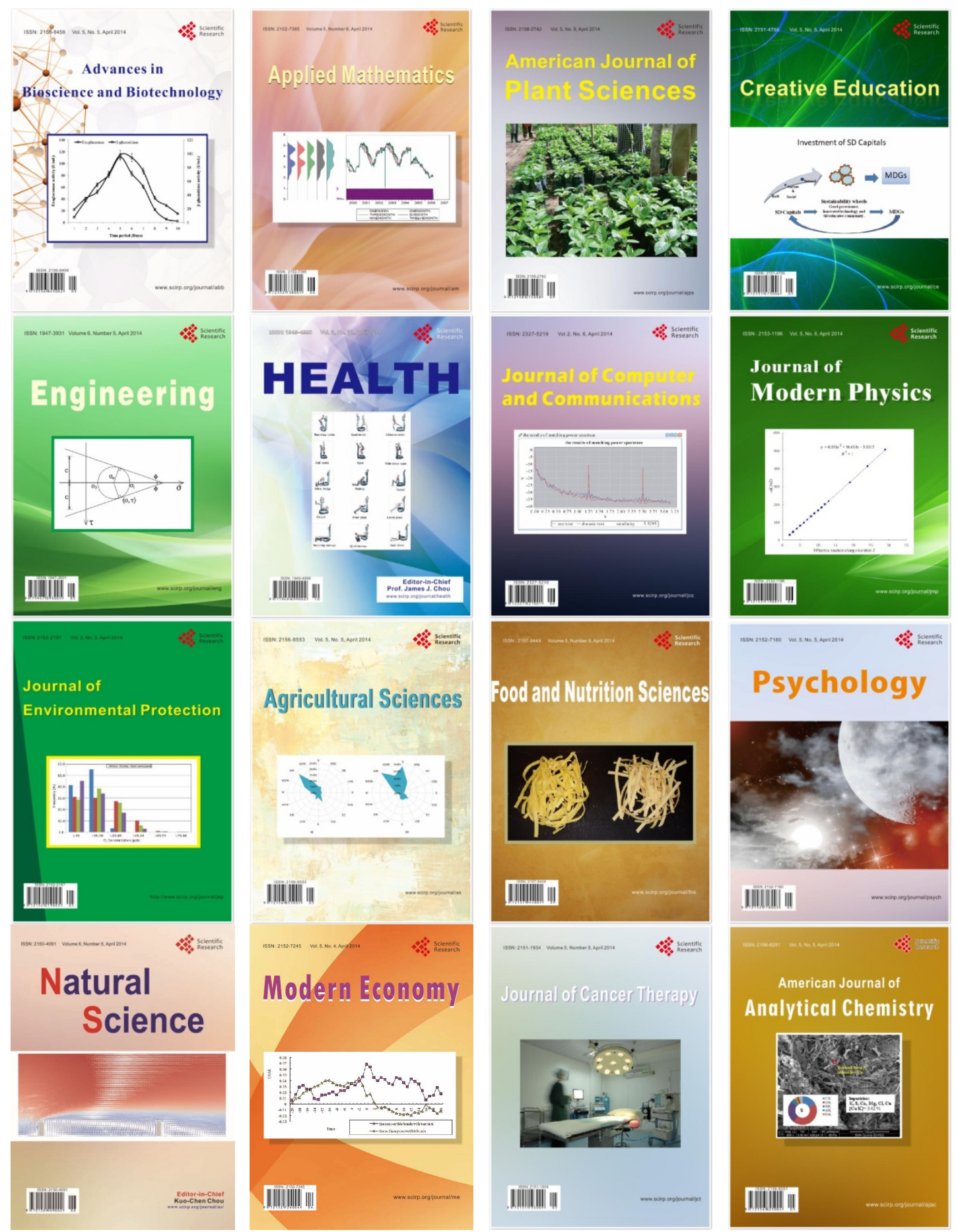